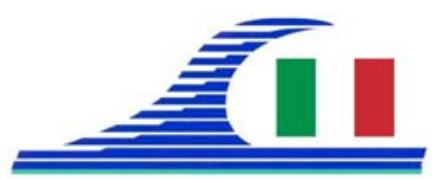

Conférence Méditerranéenne Côtière et Maritime EDITION 3, FERRARA, ITALIA (2015)

Coastal and Maritime Mediterranean Conference

Disponible en ligne - http://www.paralia.fr - Available online

\title{
Mitigating beach erosion in storm conditions with a submerged breakwater: an experimental study
}

\section{Mathieu GERVAIS ${ }^{1,2}$, Damien PHAM-VAN-BANG ${ }^{1,3}$, Vincent VIDAL $^{1,3}$, Marissa YATES $^{1,3}$, Michel BENOIT ${ }^{1,4}$}

1. Université Paris-Est, Laboratoire d'Hydraulique Saint-Venant (LHSV), ENPC, EDFR\&D, Cerema, Chatou, France. mathieu-externe.gervais@edf.fr

2. Ecole des Ponts ParisTech (ENPC), 77455 Marne-la-vallée cedex, France. mathieu.gervais@laposte.net

3. Cerema, DTecEMF, 60280 Margny-les-Compiègne, France. damien.pham-van-bang@cerema.fr ; marissa.yates-michelin@cerema.fr

4. EDF R\&D/LNHE, 78400 Chatou, France.

michel.benoit@edf.fr

\begin{abstract}
:
Sea-level rise and changes in storm frequency and intensity will undoubtedly modify beach morphology. To reduce shoreline retreat, many structural solutions have been proposed by coastal engineers. Among them, Submerged BreakWaters (SBW) are becoming a preferred solution owing to their aesthetical and environmental advantages. Here, a reduced scale physical model is used to study the reduction of storm-induced erosion for different shapes and locations of SBW's. The originality of the set-up is: (1) the 1/10 scale model beach and SBW under irregular waves; and (2) respecting sediment transport similarity. Starting with an equilibrium beach profile, a synthetic storm is tested with and without the SBW. Preliminary results show a promising reduction of erosion rates and shoreline retreat for the selected SBW geometry and location.
\end{abstract}

Keywords: Storm erosion, Submerged low-crested breakwater, Coastal engineering, ICZM, Maritime works, Beach morphodynamic, Physical model.

\section{Introduction}

The prediction of short-term cross-shore beach response to wave action is of major interest to the coastal research community and to coastal engineers. Existing beach accretion/erosion numerical models range from energetics-based, rapid empirical models of profile evolution (e.g. BAILARD, 1981) to time consuming, fine-scale physical process models accounting for wave asymmetry (e.g. GRASSO et al., 2011) and stirring turbulence (e.g. HENDERSON et al., 2004). For both of these types of numerical models, data sets from physical models remain a necessary tool to validate and improve the simulation of sediment transport during storm conditions and recovery 
Côtes méditerranéennes menacées :

Risques et défis dans le contexte du changement climatique

periods. For decades, coastal engineers have been searching for innovative solutions to counteract beach shoreline retreat, including the use of sand nourishments combined with groins, and/or low-crested shore-parallel breakwaters (LAMBERTI \& ZANUTTIGH, 2009). Submerged breakwaters (SBWs), which are narrow, reef-like structures, are now an aesthetically and environmentally favored solution. They effectively maintain an artificial perched beach with an elevated equilibrium profile by reducing the nearshore wave height and creating a sill to trap sand near the shore (DEAN, 1991). The efficiency of SBW's depends strongly on the distance between the structure and the shoreline, but RANASINGHE \& TURNER (2006) and RANASINGHE et al. (2010) suggest that there is a lack of data to validate applications using numerical simulations.

The present work investigates the cross-shore influence (2DV only) of a SBW in reducing wave action and storm beach erosion using the experimental protocol of the LEGI laboratory (GRASSO et al., 2009). Here, the protocol designed to study beach morphodynamics is extended to study the impact of an impermeable SBW, which to our knowledge has not yet been tested in reduced-scale wave tank experiments using lightweight PMMA sand.

\section{Materials and methods}

The experiments were carried out in a $36 \mathrm{~m}$ long, $0.6 \mathrm{~m}$ wide, and $0.8 \mathrm{~m}$ high wave flume equipped with a piston-type wave generator. The offshore still water depth is 0.5 $\mathrm{m}$. The sloping bottom consists of a supporting hard ramp covered by loose plastic PMMA sand (density $1.19 \mathrm{~g} \mathrm{~cm}^{-3}$ ) with a median grain diameter of $d_{50}=0.54 \mathrm{~mm}$ and settling velocity $w_{s}=1.7 \mathrm{~cm} . \mathrm{s}^{-1}$. The Froude (0.02 to 0.16$)$, Shields ( $10^{-2}$ to 3 ), and Rouse (1.5 to 15$)$ numbers correspond to those of natural environments (GRASSO et al., 2009). Underwater shoreface (2.7\%) and swash zone slopes (4-8\%) are intermediate. Time and length scale ratios are roughly $1 / 3$ and $1 / 10$, respectively. Irregular waves are generated using a JONSWAP spectrum (peak enhancement factor $\gamma=3.3$ ) for 30 min runs, and beach and shoreface bathymetry are surveyed after each run.

Thus far, three different wave climates have been tested: two "calm" wave conditions and one synthetic 9.5-h storm (wave conditions A to I; Figure 1). The storm represents a short, single-peak event typically observed in the Mediterranean Sea (e.g. GERVAIS et al., 2012) with a longer wave period Tp during the period of decreasing Hs compared to the $T p$ before the peak of the storm.

The tested SBW is an impermeable block shaped like a classic rock-armored breakwater with 1:3 side slopes (symmetric) and a flat crest (RANASINGHE et al., 2006 ; LAMBERTI et al., 2005). The top of the structure is located $0.1 \mathrm{~m}$ below the still water level, wth a height of $0.15 \mathrm{~m}$, a total length of $1.7 \mathrm{~m}$, and a flat crest of $1 \mathrm{~m}$. 


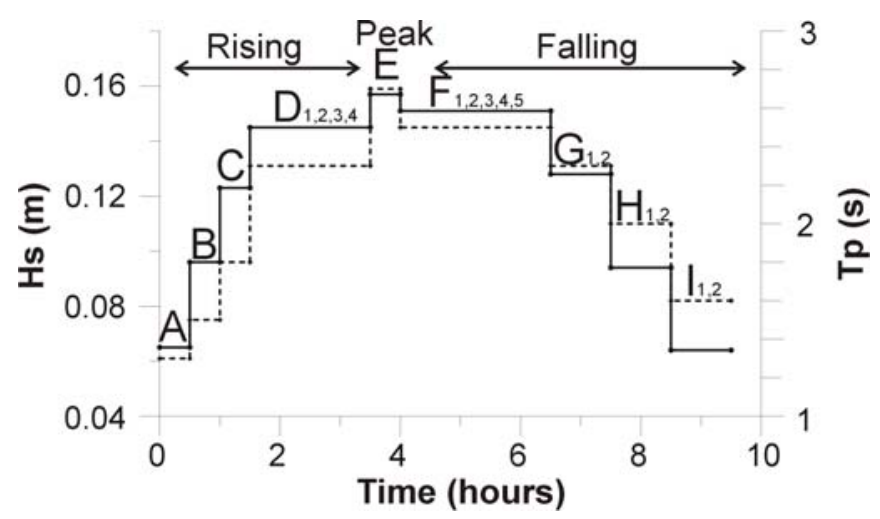

Figure 1. Synthetic storm as a sequence of varying Hs (solid line, left axis) and Tp (dashed line, right axis) wave climates (A to I).

\section{Results}

In order to investigate the cross-shore influence of the SBW, we followed the protocol of GRASSO et al. (2009) to obtain the system reference state before the storm (not presented here). We checked the repeatability and reproducibility of the equilibrium profile method, by: (1) starting from an arbitrary profile and obtaining the same overall underwater shape $(\mathrm{RMS}=0.034 \mathrm{~m})$, after $30 \mathrm{~h}$ of similar wave spectra; and (2) recreating an equilibrium profile under "calm" conditions with and without the SBW (given the initial state in Figure 2). For both cases, the profile was initially manually constructed to replicate profile "E" of GRASSO et al. (in 2009, with $H s=0.125 \mathrm{~m}$ and $T p=1.6 \mathrm{~s}$ ). Then after two hours of propagating waves, the profiles reached their equilibrium state, and in the case with the SBW, the original profile was rapidly flattened between the SBW and the shoreline (see Figure 2 B).

Figure 2 compares the resulting storm morphological response of the beach without (A) and with (B) the SBW. The change in bed level is larger without the SBW, and the structure appears to reduce erosion.

During the storm, high frequency surveys indicate that the first significant impacts on the beach appear at the beginning of climate $C$ (for both cases), but the largest changes occur with climate $D(D 1$, in particular), when $H s$ and $T p$ increase significantly. During $D 1$, a large erosion scarp is created in the not yet compacted beachface sand, and this scarp is smaller on the protected beach (with SBW). Scouring occurs on the shoreward side of the SBW, and a bar ( flat section) starts to develop on the offshore side where large waves begin to break. The short storm peak, climate $E$, slightly accelerates the morphological evolution but further changes are more progressive. Figure 3 shows that sand volume evolution on the upper (sub-aerial beach and upper shoreface) and lower (mid- and lower shoreface) parts of the profile (pivot point 9.5m from the backshore), are compensatory. The waning conditions of the storm are too short to allow significant recovery, showing the asymmetry of erosion and accretion processes (in agreement with field investigations, e.g. GERVAIS et al., 2012). 
Côtes méditerranéennes menacées :

Risques et défis dans le contexte du changement climatique
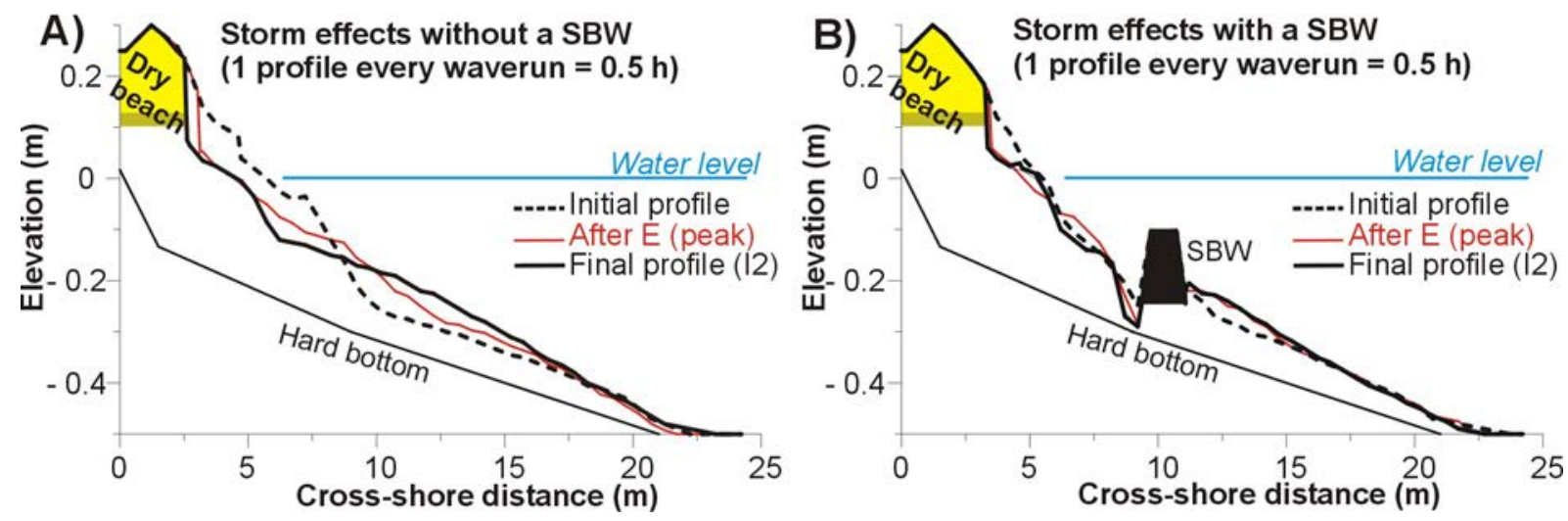

Figure 2. Impact of storm event A) without and B) with a SBW.

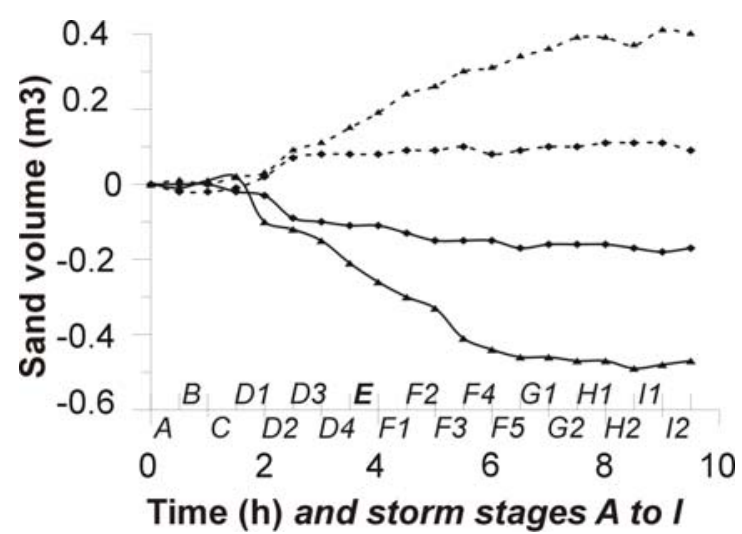

Figure 3. Volume (in $\mathrm{m}^{3}$ ) variation in between the upper (solid line) and lower (dashed line) part of the shoreface with (diamond) and without (triangle) the SBW.

\section{Conclusions}

An innovative experimental facility was set up to study the effects of a submerged structure on the cross-shore morphological response of a beach in a reduced-scale wave flume. The adopted protocol using lightweight sand producing realistic sediment transport allows reaching the equilibrium profile in 1/3 the time. A realistic storm scenario was generated with a succession of different wave climates. The presence of the SBW reduces the erosion rate by a factor of 3 on the upper shoreface during the storm, but still allows a transfer of sand seaward over the crest by suspension in return flows. However, these encouraging preliminary results likely depend strongly on the initial profile and position of the SBW. In addition, there was significant scouring on the onshore toe of the SBW that must be addressed in future research.

Future experiments will mainly consider other cross-shore locations and design shapes of the submerged structure. In addition, the impacts of varying wave conditions should be investigated by using the measurements to test existing empirical estimations or model simulations of sediment transport. 
Mediterranean coasts at threat:

Hazards and challenges in the context of climate variability

\section{Acknowledgements}

We thank Geocorail (c) for the funding of this research, Hervé Michallet, Florent Grasso and Eric Barthélémy from LEGI (Grenoble) for their helpful advice, and Stéphane Fisher, CEO of the Ubertone company for providing us new acoustic sensors for next tests.

\section{References}

BAILARD J.A. (1981). An energetics total load sediment transport model for a plane sloping beach. Journal of Geophysical Research, Vol. 86(C11), 10, pp 938-10, 954. http://dx.doi.org/10.1029/JC086iC11p10938

DEAN R.G. (1991). Equilibrium Beach Profiles: Characteristics and Applications. Journal of Coastal Research, Vol. 7(1), pp 53-84.

GERVAIS M., BALOUIN Y., BELON R. (2012). Morphological response and coastal dynamics associated with major storm events along the Gulf of Lions coastline, France. Geomorphology, vol. 143-144: 69-80. http://dx.doi.org/10.1016/j.geomorph.2011.07.035

GRASSO F, MICHALLET H., BARTHELEMY E., CERTAIN R. (2009). Physical modeling of intermediate cross-shore beach morphology: transient and equilibrium states. Journal of Geophysical Research, Vol. 114 (C09001). http://dx.doi.org/10.1029/2009JC005308

GRASSO F, MICHALLET H., BARTHELEMY E (2011). Sediment transport associated with morphological beach changes forced by irregular asymmetric, skewed waves. Journal of Geophysical Research, Vol. 116(C3), pp. 2156-2202. http://dx.doi.org/10.1029/2010JC006550

HENDERSON S.M., ALLEN J.S., NEWBERGER P.A. (2004). Nearshore sandbar migration predicted by an eddy-diffusive boundary layer model. Journal of Geophysical Research, 109(C060224), pp 2156-2202. http://dx.doi.org/10.1029/2003JC002137

LAMBERTI A., ZANUTTIGH B. (2009). Low Crested Breakwaters. Chapter 22 (pp 601-632) of Handbook of Coastal and Ocean Engineering, edited by C. KIM. World Scientific ed. http://dx.doi.org/10.1142/9789812819307_0022

LAMBERTI A., ARCHETTI R., KRAMER M., PAPHITIS D., MOSSO C., DI RISIO M. (2005). European experience of low crested structures for coastal management. Coastal Engineering, Vol. 52, pp 841-866. http://dx.doi.org/10.1016/j.coastaleng.2005.09.010

RANASINGHE R., TURNER I.L. (2006). Shoreline response to submerged structures: A review. Coastal Engineering, Vol. 53, pp 65-79. http://dx.doi.org/10.1016/j.coastaleng.2005.08.003 RANASINGHE R., LARSON M., SAVIOLI J. (2010). Shoreline response to a single shore-parallel submerged breakwater. Coastal Engineering 57, pp 1006-1017. http://dx.doi.org/10.1016/j.coastaleng.2010.06.002 
Côtes méditerranéennes menacées :

Risques et défis dans le contexte du changement climatique 